\title{
A Rapid and Sensitive UPLC-MS/MS Method for Quantification of Bruceantinol in Rat Plasma and Its Application to a Pharmaco- kinetic Study
}

\author{
Authors \\ Affiliations \\ 1 Basic Medical Science College, Liaoning University of \\ Traditional Chinese Medicine, Shenyang, China \\ 2 Key Laboratory of Ministry of Education for TCM Viscera- \\ State Theory and Applications, Liaoning University of \\ Traditional Chinese Medicine, Shenyang, China \\ 3 Department of Pharmacology, Shenyang Pharmaceutical \\ University, Shenyang, China \\ 4 Department of Medicine, University of Pittsburgh School \\ of Medicine, Pittsburgh, USA
}

Jun Li ${ }^{1,2}$, Dayong Zheng ${ }^{3}$, Bixian Zhen ${ }^{2}$, Yunfeng Sun ${ }^{1}$, Fen Chen ${ }^{2}$, Kaixuan Zhan ${ }^{2}$, Ning Wei ${ }^{4}$, Lide Zhang ${ }^{2}$

Key words

bruceantinol, UPLC-MS/MS, pharmacokinetics, bioavailability, Brucea javanica, Simaroubaceae

received April 13, 2017

revised July 5, 2017

accepted July 20, 2017

Bibliography

DOI https://doi.org/10.1055/s-0043-117414

Published online July 31, 2017 | Planta Med 2018; 84: 111-

116 @ Georg Thieme Verlag KG Stuttgart · New York I

ISSN 0032-0943

Correspondence

Prof. Dr. Lide Zhang

Key Laboratory of Ministry of Education for TCM Viscera-State

Theory and Applications, Liaoning University of Traditional

Chinese Medicine

79 East Chongshan Road, Shenyang 110032, China

Phone: + 862431207165 , Fax: + 862431207165

tougao_lee@126.com $\bigoplus \begin{aligned} & \text { Supporting information available online at } \\ & \text { http://www.thieme-connect.de/products }\end{aligned}$

\begin{abstract}
Bruceantinol (BOL), a quassinoid compound isolated from the fruits of Brucea javanica, has been reported to have cytotoxic and antibacterial effects. In this study, a rapid, sensitive, and specific ultra-performance liquid chromatography with tandem mass spectrometry (UPLC-MS/MS) method was developed for the quantitative determination of $\mathrm{BOL}$ in rat plasma. The samples were treated by simple liquid-liquid extraction with ethyl acetate and separated on an UPLC BEH C18 column (2.1 mm $\times 50 \mathrm{~mm})$ using a 3-min gradient elution scheme, which consists of water $(0.1 \% \mathrm{v} / \mathrm{v}$, formic acid) and methanol $(0.1 \%, v / v$, formic acid) to achieve the separation of BOL and sinomenine (IS) with high selectivity. The electrospray ionization source was used in positive ion mode; the multiple reaction monitoring quantified the target fragment ions $\mathrm{m} / \mathrm{z}$ $629.6 \rightarrow 569.5$ for BOL and $\mathrm{m} / \mathrm{z} 330.5 \rightarrow 207.3$ for IS. This work was evaluated with regards to the specificity, extraction recovery, matrix effect, linearity, accuracy, precision, stability, and dilution integrity. This approach was used to examine the pharmacokinetics of $\mathrm{BOL}$ in rats after oral $(0.3 \mathrm{mg} / \mathrm{kg})$ and intravenous $(0.15 \mathrm{mg} / \mathrm{kg})$ administration. BOL presented fast excretion and very low oral bioavailability.
\end{abstract}

\section{Introduction}

As an evergreen shrub, Brucea javanica (L.) Merr. (Simaroubaceae) is widespread in northern Australia and Southeast Asia [1]. In Southeast Asia, all parts of B. javanica are used as an antimalarial agent, and the fruits of this plant (such as "ya dan zi," "ya tan tzu," "kho-sam," "Macassar kernals," and "Makassaarse pitjes") are also employed as folk herbs for the treatment of various ailments, including cancer, amoebic dysentery, and skin disorders [2]. In China, $B$. javanica seed oil has long been used as an available Chinese patented medicine for the treatment of malignant tumors, such as hepatoma, lung carcinoma, prostate cancer, and breast tumor [3]. It has been observed that plants in the genus Brucea are rich in quassinoids that have a broad spectrum of biological activities, including potential antimalarial, anti-HIV, anti-tuberculosis, anti-tumor, cancer chemoprophylaxis, and cytotoxic activities [4].

Bruceantinol (BOL, $\mathrm{C}_{30} \mathrm{H}_{38} \mathrm{O}_{13}$, molecular weight 606.2, - Fig. 1) is a typical member of the quassinoid group of compounds and was isolated from the fruit of $B$. javanica and the stem bark of Brucea antidysenterica Mill. (Simaroubaceae) [5]. Notably, 


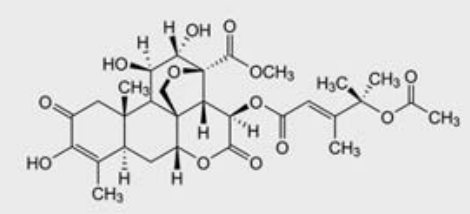

A

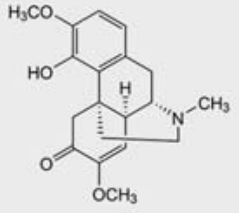

B
- Fig. 1 The chemical structure of BOL (A) and IS (B).

BOL possesses antitrypanosomal, antibabesial, and anti-tumor effects [6-9]. Additionally, its analogs, including bruceantin, bruatol, bruceine $A$, and bruceine $D$, have exhibited different biological effects, including antitrypanosomal, anthelmintic, antibabesial, hypoglycemic, and cytotoxic activities [10-14]. Several quassinoid compounds have been evaluated as novel drug candidates in preclinical or clinical trials in the 1980s $[15,16]$. However, not enough research has been performed to understand the pharmacokinetic properties of these compounds in proper animal models. To date, no quantitative analytical methods are available to determine $\mathrm{BOL}$ in biological fluids. Pharmacokinetic parameters and the bioavailability of BOL remain unknown. Thus, it is important to propose a highly reliable and accurate analytical method for quantifying $\mathrm{BOL}$ in biological samples.

A simple, selective, and highly sensitive ultra-performance liquid chromatography with tandem mass spectrometry (UPLC-MS/ MS) method was proposed and proven for the quantitative measurement of BOL in rat plasma. The chromatography run time was $3 \mathrm{~min} / \mathrm{sample}$. This approach was proposed and successfully applied in BOL pharmacokinetic studies after oral and intravenous administration to rats. It is expected that the use of this analytical method and BOL's PK (pharmacokinetics) data could be useful for future studies on BOL and its analogs.

\section{Results and Discussion}

The extraction efficiency from both the liquid-liquid extraction and protein precipitation was compared while preparing the samples. The results from the liquid-liquid extraction method were much better, as this process can remove many endogenous substances, thus improving the BOL detection limits. Several organic reagents, such as ethyl acetate, dichloromethane, methyl tert-butyl ether and diethyl ether, were examined as potential extract solvents. Ethyl acetate was chosen as the optimal solvent because it supplied more sensitive and stable extraction recoveries for BOL and sinomenine (IS) and displayed lower toxicity during sample preparation [17].

Optimization of the ionization conditions for the analysis of BOL and IS was carefully performed by adapting the UPLC-MS/MS operating parameters. Using a full-range scan in positive and negative ionization modes, the signal intensities of $\mathrm{BOL}$ and IS were evaluated through the flow injection of their authentic solutions. No signals of $\mathrm{BOL}$ were observed in negative ionization mode. In the mass spectrometer, $\mathrm{BOL}$ and $\mathrm{IS}$ yielded major $[\mathrm{M}+\mathrm{Na}]^{+}$ions at $m / z 629.6$ and $[\mathrm{M}+\mathrm{H}]^{+}$ions at $m / z$ 330.5, respectively. Thus, in multiple reaction monitoring (MRM) positive mode, $B O L$ showed the most intense transition $[\mathrm{M}+\mathrm{Na}]^{+}$at $\mathrm{m} / \mathrm{z} 629.6 \rightarrow$ 569.5 (as a quantifier) and a second transition at $\mathrm{m} / \mathrm{z} 629.6 \rightarrow$ 461.3 (as a qualifier); the most intense transition for IS was at $\mathrm{m} / \mathrm{z} 330.5 \rightarrow 207.3$. UPLC-MS/MS conditions and representative mass spectra of BOL and IS, as well as NMR spectra $\left({ }^{1} \mathrm{H},{ }^{13} \mathrm{C}, \mathrm{HSQC}\right.$, and $\mathrm{HMBC}$ ) and NMR data of BOL, are available as Supporting Information.

To achieve optimal chromatographic behaviors (with high resolution and reproducibility, symmetrical peaks, good baseline, and shorter retention times), various liquid chromatographic conditions (sorts of column; composition, $\mathrm{pH}$ value, flow rate, and proportion of mobile phase; and temperature sets) were investigated for the BOL pharmacokinetics study. Finally, a gradient mobile phase of $0.1 \%$ formic acid in water and methanol was determined because it exhibited better reproducibility and separation during the process. Under these chromatographic conditions, the retention times of $\mathrm{BOL}$ and IS were 2.16 and 0.54 min, respectively, in a run time of $3 \mathrm{~min}$. No endogenous peaks were observed at the retention times for either BOL or IS. The specificity was determined using representative chromatograms from blank plasma, lower limit of quantification (LLOQ), and the rat plasma samples. $>$ Fig. 2 shows that our assay was free of endogenous interference from all plasma analytes in the corresponding BOL and IS retention times.

The extraction recovery and matrix effects of BOL and IS in the plasma are summarized in - Table 1 . The absolute extraction recovery (\%) of BOL for quantification from the four quality control (QC) concentration levels was $82.3 \pm 4.7 \%, 86.2 \pm 5.6 \%, 90.9 \pm$ $6.1 \%$, and $85.4 \pm 5.8 \%$. Considering the matrix effects, the ratios of the MS peak response for BOL were $80.8 \pm 4.9 \%, 92.9 \pm 7.0 \%$, $83.0 \pm 3.9 \%$, and $81.4 \pm 6.8 \%$ at 2, 20, 200 , and $1000 \mathrm{ng} / \mathrm{mL}$, respectively. These results demonstrated that co-eluting plasma interference did not significantly inhibit BOL ionization and that the influence of the plasma matrix was consistent in our measurements. The BOL calibration curve exhibited nice linearity in the concentration range from $1.0-2000 \mathrm{ng} / \mathrm{mL}$. The typical standard curve was demonstrated by $y=0.001606 x+0.000287$, where $y$ represents the peak area ratio of the analytes to IS, and $x$ is the $\mathrm{BOL}$ plasma concentration. The BOL LLOQ ( $\mathbf{F i g . 2 B}$ ) was achieved at $1.0 \mathrm{ng} / \mathrm{mL}$, and at that concentration level, both the accuracy and precision were within acceptable limits $(n=6$, $S / N \geq 10$, and $R E=7.3 \%$ ). In the method for quantifying of $B O L$, the accuracy and precision were evaluated by six replicates at each QC level. The experimental data ( $\bullet$ Table 2 ) demonstrated that the intra-day and inter-day precision were $5.9-12.5 \%$ and $3.3-11.6 \%$, respectively, while accuracy was -5.8 to $6.4 \%$ and - 3.4 to $6.7 \%$, respectively. The stability test on BOL in stored samples and during preparation was conducted by analyzing four QC sample levels. All the experimental results suggested that no significant stability problems were encountered during the analysis of the plasma samples after maintaining the samples at ambient temperature for $2 \mathrm{~h}$, in the $-80^{\circ} \mathrm{C}$ for $30 \mathrm{~d}$, after three freezethaw cycles, or at $4^{\circ} \mathrm{C}$ in the autosampler for $24 \mathrm{~h}(\triangleright$ Table 3). Six repetitions with the dilution integrity samples at $5000 \mathrm{ng} / \mathrm{mL}$ were examined and recalculated as $4530.7 \pm 228.1 \mathrm{ng} / \mathrm{mL}$ (rela- 

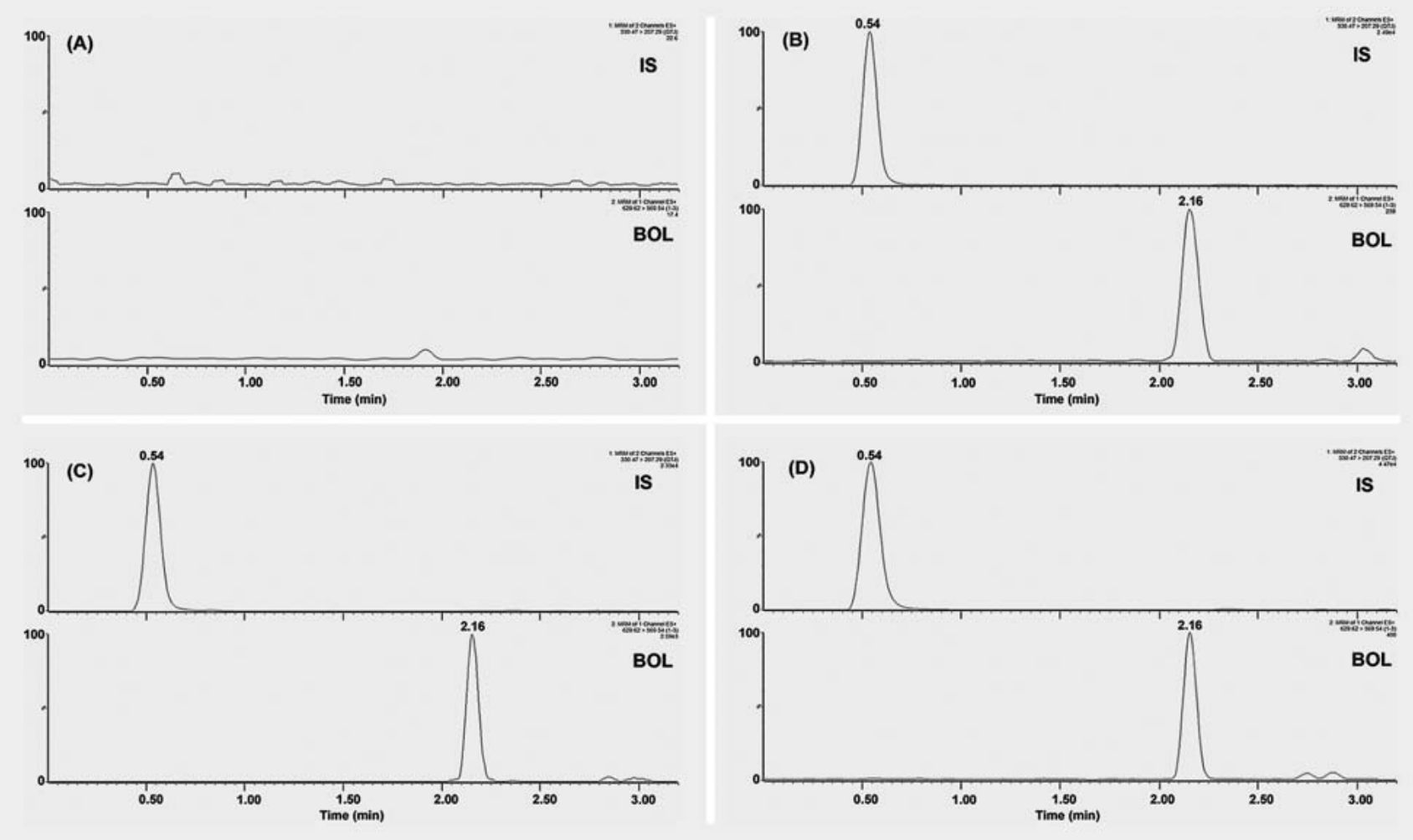

- Fig. 2 A Chromatograms of blank rat plasma; B LLOQ $(1.0 \mathrm{ng} / \mathrm{mL}) ; \mathrm{C}$ a rat plasma sample at $2 \mathrm{~h}$ after intravenous administration of BOL $(0.15 \mathrm{mg} / \mathrm{kg}) ; \mathrm{D}$ a rat plasma sample at $15 \mathrm{~min}$ after oral administration of $\mathrm{BOL}(0.3 \mathrm{mg} / \mathrm{kg})$.

- Table 1 Matrix effect and extraction recovery for determination of $\mathrm{BOL}$ in plasma $(n=6$, mean $\pm S D)$.

\begin{tabular}{|c|l|l|}
\hline $\begin{array}{c}\text { Concentration } \\
(\mathbf{n g} / \mathbf{m L})\end{array}$ & $\begin{array}{l}\text { Extraction recovery } \\
\text { (mean } \pm \text { SD [\%]) }\end{array}$ & $\begin{array}{l}\text { Matrix effect } \\
\text { (mean } \pm \text { SD [\%]) }\end{array}$ \\
\hline 2 & $82.3 \pm 4.7$ & $80.8 \pm 4.9$ \\
\hline 20 & $86.2 \pm 5.6$ & $92.9 \pm 7.0$ \\
\hline 200 & $90.9 \pm 6.1$ & $83.0 \pm 3.9$ \\
\hline 1000 & $85.4 \pm 5.8$ & $81.4 \pm 6.8$ \\
\hline
\end{tabular}

tive error [RE\%], - 9.6\%). Thus, the stability and dilution integrity are satisfactory for routine pharmacokinetics studies

The UPLC-MS/MS analytical method described here was constructed to study the pharmacokinetics of $\mathrm{BOL}$ in rats. After oral $(0.3 \mathrm{mg} / \mathrm{kg})$ and intravenous $(0.15 \mathrm{mg} / \mathrm{kg})$ administration of $\mathrm{BOL}$, the mean plasma concentration-time profile is shown in $\mathbf{F i g .} \mathbf{3}$. The main pharmacokinetic parameters from the non-compartment model analysis are listed in $>$ Table 4 . After a single intravenous dose, the plasma elimination half-life $\left(t_{1 / 2}\right)$ of $B O L$ was computed as $2.7 \pm 0.4 \mathrm{~h}$, and the total plasma clearance $\left(\mathrm{CL}_{\mathrm{z}}\right)$ was $0.4 \pm 0.1 \mathrm{~L} / \mathrm{h} / \mathrm{kg}$, while the mean volume of distribution $\left(\mathrm{V}_{\mathrm{z}}\right)$ was $1.5 \pm 0.4 \mathrm{~L} / \mathrm{kg}$. After oral administration with twice the intravenous dose, the BOL plasma concentration was very low, with a
- Table 2 Intra-day $(\mathrm{n}=6)$ and inter-day $(\mathrm{n}=18)$ precision and accuracy for assay of BOL in rat plasma.

\begin{tabular}{|l|c|c|c|c|}
\hline & $\begin{array}{l}\text { Nominal } \\
\text { concentra- } \\
\text { tion (ng/mL) }\end{array}$ & $\begin{array}{l}\text { Calculated con- } \\
\text { centration (ng/mL, } \\
\text { mean } \pm \text { SD) }\end{array}$ & RSD (\%) & RE (\%) \\
\hline \multirow{2}{*}{$\begin{array}{l}\text { Intra- } \\
\text { day }\end{array}$} & 2 & $2.0 \pm 0.2$ & 12.5 & -2.5 \\
\hline & 20 & $18.8 \pm 1.4$ & 7.4 & -5.8 \\
\hline & 200 & $201.3 \pm 11.6$ & 5.7 & 6.4 \\
\hline \multirow{2}{*}{$\begin{array}{l}\text { Inter- } \\
\text { day }\end{array}$} & 2 & $967.2 \pm 57.1$ & 5.9 & -4.6 \\
\hline & 20 & $2.1 \pm 0.1$ & 6.4 & 6.7 \\
\hline & 200 & $21.0 \pm 2.4$ & 11.6 & 4.9 \\
\hline & 1000 & $193.3 \pm 6.4$ & 3.3 & -3.4 \\
\hline
\end{tabular}

$\mathrm{C}_{\max }$ of $7.1 \pm 1.2 \mathrm{ng} / \mathrm{mL}, \mathrm{CL}_{\mathrm{z}}$ (clearance) of $27.3 \pm 11.9 \mathrm{~L} / \mathrm{h} / \mathrm{kg}$, and $t_{1 / 2}$ of $0.7 \pm 0.3 \mathrm{~h}$. Based on the AUC values, the oral absolute bioavailability was $F=\left(A_{\text {p. o. }} \times\right.$ Dose $\left._{\text {i.v. }}\right) /\left(\right.$ AUC $_{\text {i.v. }} \times$ Dose $\left._{\text {p. o. }}\right) \times 100 \%$. The absolute oral BOL bioavailability was $1.82 \pm 0.62 \%$ in rats, which means that it displays poor oral absorption efficiency or strong degradation and metabolism via gastrointestinal administration. 
- Table 3 Summary of stability of BOL in rat plasma under different storage conditions $(n=6)$.

\begin{tabular}{|c|c|c|c|c|c|c|c|c|}
\hline \multirow[t]{2}{*}{ Concentration (ng/mL) } & \multicolumn{2}{|c|}{ Room temperature (2 h) } & \multicolumn{2}{|c|}{$-80^{\circ} \mathrm{C}(30 \mathrm{~d})$} & \multicolumn{2}{|c|}{ Three freeze and thaw cycles } & \multicolumn{2}{|c|}{$4^{\circ} \mathrm{C}(24 \mathrm{~h})$} \\
\hline & RSD (\%) & RE (\%) & RSD (\%) & RE (\%) & RSD (\%) & RE (\%) & RSD (\%) & RE (\%) \\
\hline 2 & 9.5 & -9.2 & 8.6 & -14.2 & 9.5 & -1.7 & 8.2 & -8.3 \\
\hline 20 & 7.3 & -2.9 & 6.4 & -9.2 & 9.4 & -3.9 & 4.7 & -1.8 \\
\hline 200 & 3.1 & 1.8 & 4.8 & -3.7 & 2.8 & 0.7 & 8.2 & 4.7 \\
\hline 1000 & 4.7 & -3.3 & 4.0 & -3.8 & 2.1 & -3.3 & -2.4 & 1.9 \\
\hline
\end{tabular}
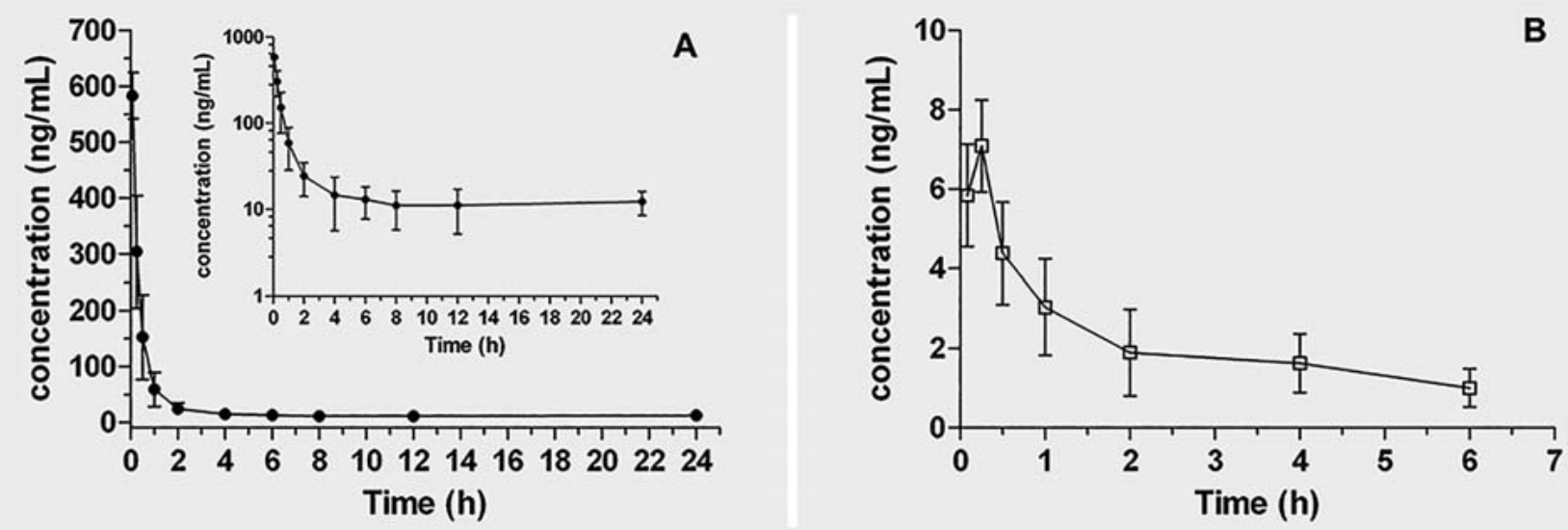

- Fig. 3 Mean plasma concentration-time curve of BOL after intravenous (A) and oral administration (B) of 0.15 and $0.3 \mathrm{mg} / \mathrm{kg}$, respectively ( $\mathrm{n}=6$ ).

In conclusion, a rapid, sensitive method based on UPLC-MS/MS was proposed and evaluated in this pharmacokinetics study of $\mathrm{BOL}$ in rats. For simplicity during operations, the plasma samples were pretreated before liquid-liquid extraction with ethyl acetate. Chromatographic separation was conducted on a C18 column with a gradient elution with methanol-water $(0.1 \%$, v/v, formic acid), and a turnover rate of $3 \mathrm{~min}$ per sample. After oral $(0.3 \mathrm{mg} / \mathrm{kg})$ and intravenous $(0.15 \mathrm{mg} / \mathrm{kg})$ administration in rats, the quantitative analysis for plasma samples was applied to determine the BOL pharmacokinetics profiles. Following a single intravenous administration, $\mathrm{BOL}$ was rapidly eliminated from rat plasma and reached a low concentration level; however, there were tiny amounts of $\mathrm{BOL}$ detected in the plasma by the oral route. Its fast excretion and low bioavailability suggested that extensive metabolism, low trans-membrane transport, or bulk degradation occurred in vivo, likely due to the ester bonds and rigid rings in the BOL chemical structure. Moreover, the esterases present in rat plasma can decompose compounds such as BOL through ester functions, which potentially led to the loss of BOL in the blood. The results described in this manuscript provide helpful information for pharmacokinetics study on $\mathrm{BOL}$ in other animal models.
- Table 4 The pharmacokinetic parameters of BOL in rat plasma after oral and intravenous administration $(n=6$, mean $\pm S D)$.

\begin{tabular}{|l|c|c|}
\hline Parameters & $\begin{array}{l}\text { Intravenous } \\
\mathbf{( 0 . 1 5} \mathbf{~ m g / k g})\end{array}$ & $\begin{array}{l}\text { Oral } \\
\mathbf{( 0 . 3 ~} \mathbf{~ m g} / \mathbf{k g})\end{array}$ \\
\hline $\mathrm{AUC}_{0-\mathrm{t}}(\mathrm{ng} / \mathrm{mL} \mathrm{h})$ & $322.2 \pm 85.7$ & $11.7 \pm 4.0$ \\
\hline $\mathrm{AUC}_{0-\infty}(\mathrm{ng} / \mathrm{mL})$ & $400.8 \pm 98.0$ & $12.7 \pm 4.3$ \\
\hline $\mathrm{MRT}_{0-\mathrm{t}}(\mathrm{ng} / \mathrm{mL})$ & $10.0 \pm 0.2$ & $2.8 \pm 0.3$ \\
\hline $\mathrm{MRT}_{0-\infty}(\mathrm{ng} / \mathrm{mL} \mathrm{h})$ & $6.1 \pm 2.1$ & $2.1 \pm 0.5$ \\
\hline $\mathrm{t}_{1 / 2}(\mathrm{~h})$ & $2.7 \pm 0.4$ & $0.7 \pm 0.3$ \\
\hline $\mathrm{T}_{\max }(\mathrm{h})$ & $0.083 \pm 0$ & $0.194 \pm 0.086$ \\
\hline $\mathrm{V}_{\mathrm{z}}(\mathrm{L} / \mathrm{kg})$ & $1.5 \pm 0.4$ & $24.8 \pm 7.6$ \\
\hline $\mathrm{CL}_{\mathrm{z}}(\mathrm{L} / \mathrm{h} / \mathrm{kg})$ & $0.4 \pm 0.1$ & $27.3 \pm 11.9$ \\
\hline $\mathrm{C}_{\max }(\mathrm{ng} / \mathrm{mL})$ & $616.8 \pm 40.8$ & $7.1 \pm 1.2$ \\
\hline Absolute bioavailability & & $1.82 \pm 0.62 \%$ \\
\hline $\mathrm{MRT}$ : mean residence time & & \\
\hline
\end{tabular}




\section{Materials and Methods}

\section{Materials}

BOL (purity $>98.0 \%$, $>$ Fig. 1 ) and IS (purity $>98.0 \%$ ) were supplied by Beijing Oriental Xintai Biological Technology Co., Ltd. HPLC-grade methanol and acetonitrile were purchased from Merck. Calcium heparin was from Tianjin Biochem Pharmaceutical Co., Ltd. LC/MS-grade formic acid was bought from Fisher Scientific. All the other reagents were of analytical grade. Ultra-pure water came from a Milli-Q water purification system (Millipore Corp.).

\section{UPLC-MS/MS condition}

The UPLC-MS/MS consisted of an Acquity ultra-performance liquid chromatography system with an XEVO TQD triple quadrupole mass spectrometer, which was equipped with an electrospray ionization (ESI) source for mass spectrometry (Waters Corp.). Chromatography was performed on an Acquity BEH column (C18 Waters, $1.7 \mu \mathrm{m}, 2.1 \mathrm{~mm} \times 50 \mathrm{~mm}$ ) attached to a stainless steel frit filter $(0.2 \mu \mathrm{m})$. The temperature of column was controlled at $35^{\circ} \mathrm{C}$.

During separation, a gradient elution program was conducted using the following mixtures of organic $A$ (methanol, $0.1 \%, v / v$, formic acid) and aqueous $B$ (water, $0.1 \%, v / v$, formic acid) in media: $0-0.5 \min (40-60 \%$ A), 0.5-1.0 min (60-98\% A), 1.0-2.4 min $(98-98 \% A), 2.4-2.6 \min (98-40 \% A)$, and $2.6-3.0 \mathrm{~min}(40-40 \%$ A). The rate of flow was set as $0.3 \mathrm{~mL} / \mathrm{min}$. A $10 \mu \mathrm{L}$ aliquot of the sample solution was applied for analysis. Mass spectrometry was conducted with a +ESI method with the following optimal settings: nitrogen as the nebulizer gas, cone gas: $50 \mathrm{~L} / \mathrm{h}$, and desolvation gas: $800 \mathrm{~L} / \mathrm{h}$, source temperature: $150^{\circ} \mathrm{C}$, desolvation temperature: $400^{\circ} \mathrm{C}$, cone voltage: $78 \mathrm{~V}$, capillary voltage: $3.30 \mathrm{kV}$, argon as collision gas, collision voltage: $30 \mathrm{eV}$ and collision-induces dissociation. Detection and quantification of all the analytes was conducted under the MRM condition using the unit mass resolution for the characteristic precursor ion $\rightarrow$ product ion transition pairs. The MRM transition pairs were $\mathrm{m} / \mathrm{z} 629.6 \rightarrow 569.5$ and $\mathrm{m} / \mathrm{z}$ $330.5 \rightarrow 207.3$ for BOL and IS, respectively. The data acquisition and system control software was Masslynx 4.1 (Waters Corp.).

\section{Preparation of calibration standards and QC samples}

A stock solution of BOL $(1 \mathrm{mg} / \mathrm{mL})$ and $\mathrm{IS}(200 \mu \mathrm{g} / \mathrm{mL})$ was prepared in methanol. Then, fresh BOL working solutions with different concentrations were prepared by diluting the primary stock solution with methanol. A calibration standard and a QC sample were obtained by adding $10 \mu \mathrm{L}$ of the corresponding BOL working solution to $90 \mu \mathrm{L}$ of blank rat plasma. Thus, the final concentrations of the calibration standards were 1, 5, 10, 50, 100, 500, 1000 , and $2000 \mathrm{ng} / \mathrm{mL}$ for BOL, and the QC samples were 2, 20, 200 , and $1000 \mathrm{ng} / \mathrm{mL}$ for BOL. The IS working solution $(2 \mu \mathrm{g} / \mathrm{mL})$ was prepared by diluting the IS stock with methanol. All the experimental samples were stored at $-80^{\circ} \mathrm{C}$ until analysis.

\section{Sample preparation}

Before analysis, all samples previously stored at $-80^{\circ} \mathrm{C}$ were thawed at room temperature. In a $1.5 \mathrm{~mL}$ v-bottom Eppendorf tube, a $10-\mu \mathrm{L}$ aliquot of the IS working solution $(2 \mu \mathrm{g} / \mathrm{mL})$ was added to $100 \mu \mathrm{L}$ of each sample. The mixture was immediately homogenized with a vortex-mixer for $1 \mathrm{~min}$ and extracted with $1 \mathrm{~mL}$ of ethyl acetate by vortex-mixing for approximately $5 \mathrm{~min}$. Next, each sample was centrifuged ( $5 \mathrm{~min}$ at $16000 \times \mathrm{g}$ ), the resulting supernatant (approximately $1 \mathrm{~mL}$ ) was carefully transferred into a new $2 \mathrm{~mL}$ tube, and the organic solvent was discarded at $40^{\circ} \mathrm{C}$ with a stream of nitrogen. The residues were reconstituted with $100 \mu \mathrm{L}$ of methanol:water $(4: 6, v / v)$ and then vortexed for $5 \mathrm{~min}$. Finally, the mixture was centrifuged at $16000 \times \mathrm{g}$ for $8 \mathrm{~min}$ and the resulting supernatant $(10 \mu \mathrm{L})$ injected for continuous UPLC-MS/MS analysis.

\section{Bioanalytical method validation}

Development and validation of the method for quantifying BOL was conducted in line with the U.S. Food and Drug Administration Guidelines [18].

The selectivity of the approach was tested by analyzing blank plasma samples from six different rats to test the potential interference of endogenous substances with BOL and IS. The procedure for handling the blank plasma samples was the same as described in the "Sample preparation" section.

The matrix effect on ionization efficiency was investigated with blank plasma extracts (six rats) and water extracts spiked to equivalent QC concentration levels (2, 20, 200, and $1000 \mathrm{ng} / \mathrm{mL})$. The extraction recovery of $\mathrm{BOL}$ was tested by comparing the $\mathrm{BOL}$ peak areas from the extracted $\mathrm{QC}$ samples and those from the aqueous standard solutions at four different concentration levels. The matrix effect and extraction recovery of IS were evaluated in a manner similar to BOL at a concentration of $200 \mathrm{ng} / \mathrm{mL}$.

To evaluate the linearity, eight BOL $(1-2000 \mathrm{ng} / \mathrm{mL})$ concentrations were calibrated and tested for three consecutive days. The linearity of $\mathrm{BOL}$ was tested using ( $1 / \mathrm{x}^{2}$ weighted) least squares linear regression based on the peak area ratios of $\mathrm{BOL}$ and IS versus the BOL nominal concentrations. For sensitivity purposes, the LLOQ was tested by assaying six independent plasma samples at the lowest concentrations on the calibration curve $(1 \mathrm{ng} / \mathrm{mL})$; the precision (relative standard deviation, RSD\%) and accuracy (RE\%) must be within $\pm 20 \%$ and the signal/noise $(S / N)>10$.

The intra-day precision and accuracy of the UPLC-MS/MS method were measured by examining six individual spiked samples of BOL at each QC level (2, 20, 200, and $1000 \mathrm{ng} / \mathrm{mL})$. The inter-day values were further verified by analyzing 24 QC samples in three different validation periods. The allowed precision and accuracy for the quantification of BOL were as follows: the RSD was within $15 \%$, and the RE ranged between $-15 \%$ and $15 \%$.

BOL stability in the biological matrix and in the reconstituted solution were assessed at four QC concentration levels under the following storage situations: short-term stability, maintained at room temperature for $2 \mathrm{~h}$; long-term stability, in the $-80^{\circ} \mathrm{C}$ for $30 \mathrm{~d}$; freeze-thaw stability, after three freeze-thaw cycles; and post-preparation stability, in the $4^{\circ} \mathrm{C}$ autosampler for $24 \mathrm{~h}$. The dilution integrity was tested by analyzing six parallel samples spiked with $5000 \mathrm{ng} / \mathrm{mL}$ of BOL. The six analytes were diluted five-fold with blank rat plasma and assayed, and then the BOL concentrations, RSD\%, and RE\% were calculated. 


\section{Animals and pharmacokinetic study}

Twelve male Sprague-Dawley rats $(270 \pm 30 \mathrm{~g})$ were obtained from the Experimental Animal Center of Liaoning University of Traditional Chinese Medicine (Shenyang, China). All the experimental steps were supported by the Animal Ethics Committee of Liaoning University of Traditional Chinese Medicine (March 5, 2015; No: 201503051). For evaluating the bioavailability and pharmacokinetics behavior of BOL, the mice were randomly divided into two groups (oral and intravenous administration groups). Before the experiments, all the rats were fasted for $12 \mathrm{~h}$, though water was supplied ad libitum. The dosages for the oral and intravenous administration groups were 0.3 and $0.15 \mathrm{mg} / \mathrm{kg}$, respectively. After that, blood samples (approximately $300 \mu \mathrm{L}$ ) were drawn from the tail veins into heparinized Eppendorf tubes at $0.083,0.25,0.5,1,2,4,6,8,12$, and $24 \mathrm{~h}$. These tubes were centrifuge at $16,000 \times \mathrm{g}$ for $5 \mathrm{~min}$ at $4{ }^{\circ} \mathrm{C}$, and then each supernatant fraction $(>100 \mu \mathrm{L})$ was carefully transferred into another clean prelabeled Eppendorf tube and maintained at $-80^{\circ} \mathrm{C}$.

The pharmacokinetics parameters were computed with the Drug and Statistical software (Shanghai, China Pharmacology and Pharmacology Program version 2.1) with a non-compartmental model.

\section{Supporting Information}

UPLC-MS/MS conditions and representative mass spectra of BOL and IS, as well as NMR spectra $\left({ }^{1} \mathrm{H},{ }^{13} \mathrm{C}, \mathrm{HSQC}\right.$, and $\left.\mathrm{HMBC}\right)$ and NMR data of BOL, are available as Supporting Information.

\section{Acknowledgements}

This study was financially supported by China Postdoctoral Science Foundation (No. 2015M570257) and the Open fund of Key Laboratory of Ministry of Education for TCM Viscera-State Theory and Applications (No. 2014001021).

\section{Conflict of Interest}

We declare that we have no conflicts of interest.

\section{References}

[1] Liu JH, Zhao N, Zhang G], Yu SS, Wu LJ, Qu J, Ma SG, Chen XG, Zhang TQ, Bai J, Chen H, Fang ZF, Zhao F. Bioactive quassinoids from the seeds of Brucea javanica. J Nat Prod 2012; 75: 683-688

[2] O'Neill M], Bray DH, Boardman P, Chan KL, Phillipson JD, Warhurst DC, Peters W. Plants as sources of antimalarial drugs, part 4: activity of Brucea javanica fruits against chloroquine-resistant plasmodium falciparum in vitro and against plasmodium berghei in vivo. J Nat Prod 1987; 50: 4148
[3] Liu TT, Mu LQ, Dai W, Wang CB, Liu XY, Xiang DX. Preparation, characterization, and evaluation of antitumor effect of Brucea javanica oil cationic nanoemulsions. Int J Nanomed 2016; 11: 2515-2529

[4] Zhang ZK, Ouyang M, Zhan JS, Wu Z]. Quassinoids from Brucea javanica seeds inhibiting the replication of tobacco mosaic virus. Curr Bioact Compd 2013; 9: 247-254

[5] Kupchan SM, Britton RW, Lacadie JA, Ziegler MF, Sigel CW. Tumor inhibitors. 100. Isolation and structural elucidation of bruceantin and bruceantinol, new potent antileukemic quassinoids from Brucea antidysenterica. J Org Chem 1975; 40: 648-654

[6] Elkhateeb A, Tosa Y, Matsuura H, Nabeta K, Katakura K. Antitrypanosomal activities of acetylated bruceines $\mathrm{A}$ and $\mathrm{C}$; a structure-activity relationship study. J Nat Med 2012; 66: 233-240

[7] Ye QM, Bai LL, Hu SZ, Tian HY, Ruan LJ, Tan YF, Hu LP, Ye WC, Zhang DM, Jiang RW. Isolation, chemotaxonomic significance and cytotoxic effects of quassinoids from Brucea javanica. Fitoterapia 2015; 105: 66-72

[8] Bawm S, Matsuura H, Elkhateeb A, Nabeta K, Subeki, Nonaka N, Oku Y, Katakura K. In vitro antitrypanosomal activities of quassinoid compounds from the fruits of a medicinal plant, Brucea javanica. Vet Parasitol 2008; 158: 288-294

[9] Subeki, Matsuura H, Takahashi K, Nabeta K, Yamasaki M, Maede Y, Katakura K. Screening of Indonesian medicinal plant extracts for antibabesial activity and isolation of new quassinoids from Brucea javanica. J Nat Prod 2007; 70: 1654-1657

[10] Lau ST, Lin ZX, Liao Y, Zhao M, Cheng CH, Leung PS. Brucein D induces apoptosis in pancreatic adenocarcinoma cell line PANC-1 through the activation of p38-mitogen activated protein kinase. Cancer Lett 2009; 281: 42-52

[11] Ren D, Villeneuve NF, jiang T, Wu T, Lau A, Toppin HA, Zhang DD. Brusatol enhances the efficacy of chemotherapy by inhibiting the Nrf2-mediated defense mechanism. P Natl Acad Sci U S A 2011; 108: 1433-1438

[12] Wang Y, Wu ZF, Wang GX, Wang F, Liu YT, Li FY, Han J. In vivo anthelmintic activity of bruceine $A$ and bruceine $D$ from Brucea javanica against Dactylogyrus intermedius (Monogenea) in goldfish (Carassius auratus). Vet Parasitol 2011; 177: 127-133

[13] Issa ME, Berndt S, Carpentier G, Pezzuto JM, Cuendet M. Bruceantin inhibits multiple myeloma cancer stem cell proliferation. Cancer Biol Ther 2016; 17: 966-975

[14] Suling WJ, Woolley CW, Shannon WM. Disposition and metabolism of bruceantin in the mouse. Cancer Chemoth Pharm 1979; 3: 171-176

[15] Wiseman CL, Yap HY, Bedikian AY, Bodey GP, Blumenschein GR. Phase II trial of bruceantin in metastatic breast carcinoma. Am J Clin Onco 1982; 5: 389-391

[16] Arseneau JC, Wolter JM, Kuperminc M, Ruckdeschel JC. A phase II study of bruceantin (NSC-165, 563) in advanced malignant melanoma. Invest New Drug 1983; 1: 239-242

[17] Fan J, Guan L, Kou Z, Feng F, Zhang Y, Liu W. Determination of chrysotoxine in rat plasma by liquid chromatography-tandem mass spectrometry and its application to a rat pharmacokinetic study. J Chromatogr B 2014; 967: 57-62

[18] U.S. Department of Health and Human Services, Food and Drug Administration. Guidance for Industry: Bioanalytical Method Validation. Rockville: Center for Drug Evaluation and Research; 2013 